\title{
Review: depot antipsychotics are effective and safe for schizophrenia or schizophrenia like illnesses
}

Adams CE, Fenton MK, Quraishi S, et al. Systematic meta-review of depot antipsychotic drugs for people with schizophrenia. Br J Psychiatry 2001 Oct;179:290-9.

QUESTION: In people with schizophrenia, are depot antipsychotics (DAPs) effective?

\section{Data sources}

Reviews were identified by searching the Cochrane Library in 2000.

\section{Study selection}

Reviews were selected if they compared long acting DAPs with placebo or oral medication or compared different doses or types of DAPs for schizophrenia or schizophrenia like illnesses.

\section{Data extraction}

Data were extracted on patient and study characteristics, interventions, and outcomes.

\section{Main results}

9 reviews were included. Duration of the studies in the reviews ranged from 2 weeks to 5 years. The table showsthe results. Fewer people on DAPs than on placebo relapsed (1 review), left the study early (3 reviews), or had dry mouth or blurred vision (2 reviews); movement disorder was greater in the DAP group than in placebo group (1 review). DAPs were better than oral antipsychotics for clinically meaningful change (3 reviews); groups did not differ for relapse, movement disorder, tardive dyskinesia (TD), study attrition, or death. Studies comparing types of DAPs could not be pooled without counting participants twice; the data did not show consistent differences among DAPs. Standard dose DAPs were better than low dose DAPs for preventing relapse (number needed to treat 7, 95\% CI 5 to 12 ).

\section{Conclusions}

In people with schizophrenia, depot antipsychotics (DAPs) are better than placebo for reducing relapse rates but they increase movement disorders. DAPs do not differ from oral antipsychotics for relapse or adverse events.

Depot antipsychotic drugs (DAP) for schizophrenia or schizophrenia like illness*

\begin{tabular}{|c|c|c|c|c|c|}
\hline Outcomes at $\leqslant 2$ years & DAP & Control & $\begin{array}{l}\text { Weighted } \\
\text { event rates }\end{array}$ & RRR $(95 \%$ Cl) & NNT (Cl) \\
\hline Relapse & Fph & Placebo & $18 \%$ v $60 \%$ & $70 \%(59$ to 78$)$ & 2 (2 to 3$)$ \\
\hline Attrition & $\mathrm{Br}$, fph, ha & Placebo & $19 \%$ v $49 \%$ & $57 \%(29$ to 73$)$ & $4(3$ to 10$) \dagger$ \\
\hline \multirow[t]{2}{*}{ Dry mouth or blurred vision } & $\mathrm{Br}$, ha & Placebo & $3.9 \% \vee 35 \%$ & $84 \%(19$ to 97$)$ & $3(2$ to 9$)$ \\
\hline & & & & RRI (Cl) & NNH (Cl) \\
\hline Death & Fph & Placebo & NR & $400 \%(-75$ to 9800$)$ & Not significant \\
\hline Movement disorder & Fph & Placebo & $35 \% \vee \quad 0 \%$ & $1954 \%$ (25 to 23796$)$ & $3(2$ to 7$)$ \\
\hline Death & Fph & $\mathrm{OA}$ & $2.6 \% \vee 1.3 \%$ & $100 \%(-81$ to 2061$)$ & Not significant \\
\hline Leaving study early & Fpe, fph, pip, fsp & $\mathrm{OA}$ & $54 \%$ v $22 \%$ & $14 \%(-10$ to 45$)$ & Not significant \\
\hline \multirow[t]{2}{*}{ Movement disorder } & Fpe, fph, fsp, pip, ha & OA & $83 \%$ v $66 \%$ & $8 \%(-10$ to 30$)$ & Not significant \\
\hline & & & & $\operatorname{RRR}(\mathrm{Cl})$ & NNT (Cl) \\
\hline No important global change & Fph, FE, ha & OA & $55 \%$ v $81 \%$ & $32 \%(14$ to 46$)$ & $4(3$ to 9$)$ \\
\hline Relapse & Fph, fsp, pip & $\mathrm{OA}$ & $36 \%$ v $36 \%$ & $4 \%(-14$ to 20$)$ & Not significant \\
\hline Tardive dyskinesia & Fph, pip & $\mathrm{OA}$ & $11 \%$ v $14 \%$ & $34 \%(-30$ to 67$)$ & Not significant \\
\hline
\end{tabular}

*Br=bromperidol decanoate; $\mathrm{FE}=$ fluphenazine enanthate; Fpe=flupentixol decanoate; $\mathrm{Fph}=$ fluphenazine decanoate; Fsp=fluspirilene decanoate; $\mathrm{Ha}=$ haloperido decanoate; $\mathrm{NR}=$ not reported; $\mathrm{OA}=$ oral antipsychotics; Pip=pipotiazine palmitate. Other abbreviations defined in glossary; weighted event rates, RRR, RRI, and $\mathrm{Cl}$ calculated from data in article using a random effects model. †Calculated from data in article using a random effects model.

\section{COMMENTARY}

In contrast to other serious mental and physical disorders, the use of DAPs for schizophrenia is prevalent. Although historical and some clinical reasons partly justify this, many patients and clinicians do not feel comfortable about it, as Adams $e t$ al acknowledge. They point out that patients' views were not sought in a systematic manner. No other common disorder features such widespread use of this route of administration and, although it is justified as a treatment of last resort for some patient subgroups, in other situations it tends to be used in a premature and potentially dehumanising manner as a shortcut to better compliance. Even if better efficacy or effectiveness were demonstrable for depot, other considerations clearly exist.

The validity of the study methods is uncertain, as the authors admit, since it is a meta-review of earlier reviews, each of which would be subject to bias. The original studies were not examined directly. Nevertheless, the study's conclusions seem appropriate. However, at least in North America and Australia, the study is obsolete, since the advent of oral atypical antipsychotics has substantially changed the risk-benefit landscape. In particular, adherence to oral drugs seems to have increased, and the risk of TD has reduced. ${ }^{12}$ The recognition that psychosocial interventions play a major role in promoting patient acceptance of their illness and the need for medication ${ }^{3}$ means that DAPs should be reserved for those situations where these methods have failed to achieve acceptable adherence and the consequences of relapse are so serious that the latitude for learning to self manage the illness is limited. Even this last resort model may not be valid given that this review showed that relapse rates do not seem to be reduced by the use of DAPs relative to oral antipsychotics. On the other hand, this study may not be especially representative and other less compliant patients who usually refuse research participation may still benefit. The conclusions of the original article seem valid for the era of first generation antipsychotics and an environment deprived of psychosocial interventions. Better outcomes should be achievable with integrated use of new drug and psychosocial interventions, and it is these that should be compared in future research with DAPs. As the authors suggest, research should focus on defining the specific indications and subgroups for optimal use of DAPs.

1 Moore DB, Kelly DL, Sherr JD, et al. Rehospitalization rates for depot antipsychotics and pharmacoeconomic implications: comparison with risperidone. Am J Health Syst Pharm 1998;55 (24 Suppl 4):S17-9.

2 Tollefson GD, Beasley CM Jr, Tamura RN, et al. Blind, controlled, long-term study of the comparative incidence of treatment-emergent tardive dyskinesia with olanzapine or haloperidol. Am J Psychiatry 1997:154:1248-54.

3 Kemp RA, David AS. Insight and adherence to treatment in psychotic disorders. Br J Hosp Med 1995;54:222-7. 